Missbrauch, Vernachlässigung, Armut

\section{Unglückliche Kindheit stört Blutdruckregulation langfristig}

\section{Traumatische Kindheitserlebnisse legen den Grundstein für die Entwicklung einer gestörten Blutdruckregulation und eines nächtlichen Bluthochdrucks bereits im jungen Erwachsenenalter.}

_ Vernachlässigung und Missbrauch, aber auch Armut und familiäre Probleme in der frühen Kindheit haben langfristige Folgen für die kardiovaskuläre Gesundheit. Schon in früheren Studien hat eine Autorengruppe um Dr. Shaoyong Su vom Augusta University Medical College in Georgia berichtet, dass negative Kindheitserlebnisse zu einem frühen Hypertonie-Leiden führen.

In einer neuen Studie haben sie nun bei 373 Personen im Alter über 23 Jahre wiederholte 24-Stunden-Blutdruckmes- sungen durchgeführt. Bei Personen, die über negative Kindheitserlebnisse berichteten, fanden sich signifikant häufiger erhöhte nächtliche Blutdruckwerte sowie eine erhöhte Blutdruckvariabilität am Tag.

Eine erhöhte Blutdruckvariabilität im frühen Erwachsenenalter kann später zu Gesundheitsproblemen führen, z. B. zu kognitiven Problemen und schweren Schlaganfällen. Auch eine frühe Hypertonie-Manifestation kann kardiovaskulären Komplikationen nach sich ziehen.

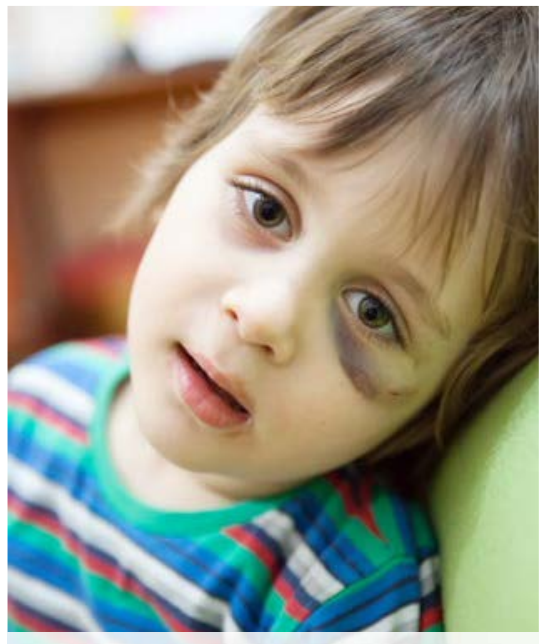

Traurige Kindheit schadet dem Herzen.

Die Autoren empfehlen die Frage nach einer schwierigen Kindheit als einfache Maßnahme, um frühzeitig kardiovaskuläre Risiken zu erfassen und gegenzusteuern.

- American Heart Association, Scientific Sessions 2016, New Orleans, 12.-16. November 2016

\title{
Genetischer Geschmacksdefekt fördert Salz- und Fettkonsum
}

\author{
Personen mit einer genetisch bedingten Geschmacksstörung neigen dazu, \\ mehr Salz, Alkohol und ungesättigte Fette zu verzehren.
}

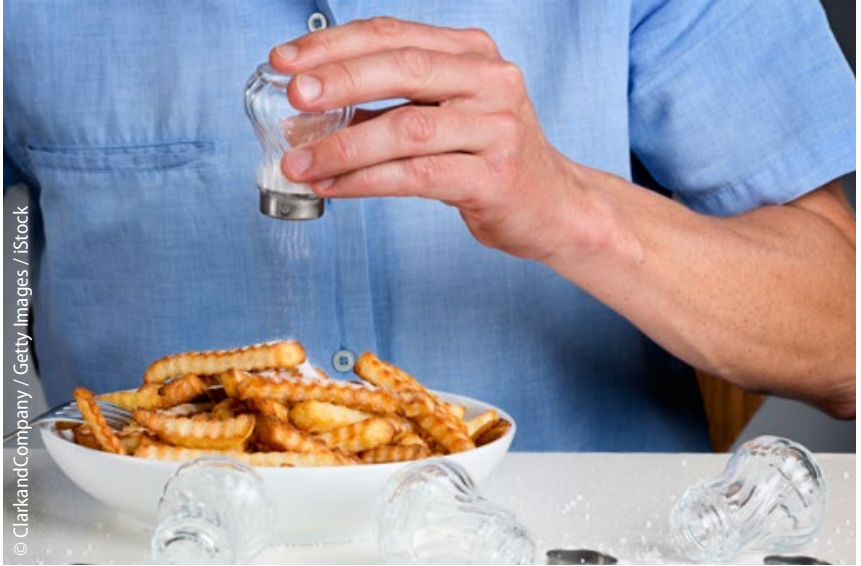

Steckt die Gier nach Salz und Fett in den Genen?
Es ist nicht immer nur eine Charakterfrage, wenn sich ungesunde Ernährungsgewohnheiten einschleichen. Offenbar kann es auch in den Genen liegen. Wer Varianten im sog. TAS2R38Gen aufweist und dadurch bittere Geschmacksrichtungen mit deutlicher Verstärkung wahrnimmt, trifft andere Entscheidungen bei der Speisenwahl.
Forscher der Universität Kentucky haben die Ernährungsgewohnheiten von 400 Personen mit kardiovaskulären Risikofaktoren analysiert und gleichzeitig nach Veränderungen im Gen für den bitteren Geschmack geforscht. Sie fanden heraus, dass im Vergleich zu Personen ohne Gendefekt doppelt so viele Personen mit verstärkter Wahrnehmung von bitterem Geschmack mehr Salz konsumierten, als es der Gesundheit förderlich ist.

- American Heart Association, Scientific Sessions 2016 New Orleans, 12.-16. November 2016 